\title{
La planta municipal y las entidades locales menores en Castilla y León
}

\author{
Antonio Calonge Velázquez \\ Profesor Titular de Derecho Administrativo \\ Universidad de Valladolid
}

\begin{abstract}
Sumario: I. INTRODUCCIÓN. II. LA ESTRUCTURA TERRITORIAL MUNICIPAL DE CASTILLA Y LEÓN. III. COMPETENCIAS DE CASTILLA Y LEÓN SOBRE LA ESTRUCTURA TERRITORIAL LOCAL. IV. LAS NORMAS CASTELLANO Y LEONESAS SOBRE LA ESTRUCTURA MUNICIPAL. 1. El Decreto para el fomento de las Mancomunidades Municipales. 2. El Proyecto de Ley Municipal de Castilla y León. 3. La Ley de Régimen Local de Castilla y León: Ley 1/1998, de 4 de junio. V. LA ORDENACIÓN DEL TERRITORIO.
\end{abstract}

\section{INTRODUCCIÓN}

La proliferación de municipios en España, su diversidad geográfica y su escasa, en muchas ocasiones, población, ha sido, es y, de no adoptarse medidas extremas, seguirá siendo, en mi opinión, un grave problema ${ }^{1}$. España, con poco más de cuarenta millones de habitantes, cuenta con 8.097 municipios asentados en $505.999 \mathrm{Km}^{2}$, de los que el 60,45 por 100 tiene una población inferior a 1.000 habitantes, lo que da lugar a una planta municipal que muchos autores califican de inframunicipal ${ }^{2}$. La Administración local española, ciertamente, se caracteriza, entre otras cosas, por una gran diseminación, constituyendo una organización territorial de base que está integrada en su mayoría por una multitud de municipios de muy pequeño tamaño poblacional.

La solución a esta situación debe buscarse con imperiosa urgencia si no queremos que, en nuestro Estado social y democrático de Derecho, pueda hablarse con propiedad de ciudadanos de primera y de ciudadanos de tercera, al menos, desde el punto de vista de la prestación de los servicios públicos y en atención al municipio en el que residan. En efecto, los

\footnotetext{
' De «enfermedad crónica del Estado, sea cual sea el sistema político imperante», la califica - a mi juicio, con acierto-R. Barranco Vela, Creación y segregación de municipios, Marcial Pons, Madrid, 1993, p. 22.

2 E. Carrillo Barroso, «La Administración municipal rural: los obstáculos de la reforma», REDA n. ${ }^{\circ} 50,1986$, p. 243, habla de Administración municipal rural para referirse a municipios de menos de 5.000 habitantes y de inframunicipios para hablar de los de menos de 1.000 .
} 
habitantes de los grandes municipios disponen de todos los servicios propios del Estado de bienestar en que vivimos, mientras que los habitantes de los pequeños municipios carecen, en buen número de casos, incluso, de los servicios municipales obligatorios establecidos por la vigente legislación de régimen local ${ }^{3}$.

El problema de la planta municipal en nuestro país aparece, casi, con la formación de los Ayuntamientos constitucionales al promulgarse la Constitución de 1812 siguiendo, como en otros países de la Europa continental, el criterio francés de erigir en municipio cualquier «ville, bourg, paroisse, ou communauté de campagne». El texto constitucional gaditano disponía en su artículo 310 que «se pondrá Ayuntamiento en los pueblos que no lo tengan y en que convenga que los haya», esbozando, después, el Decreto CLXIII, de 23 de mayo de 1812, un procedimiento para la adquisición de la calidad de Ayuntamiento, que hacía equivalente núcleo de población y municipio-Ayuntamiento ${ }^{4}$.

A partir de aquí, un somero repaso a las sucesivas leyes de régimen local de los dos últimos siglos nos permitiría observar que todas ellas, con mayor o menor extensión, se refieren a este problema de la planta municipal ${ }^{5}$. Y, asimismo - y ello es más importante-, que realmente nunca se ha querido abordar el problema en profundidad y con ganas de solucionarlo. Es más, casi todas las leyes de régimen local comenzaban estableciendo el

\footnotetext{
${ }^{3}$ Como es sabido, el artículo 26 de la Ley 7/1985, de 2 de abril, Reguladora de las Bases de Régimen Local, establece los servicios municipales obligatorios que deberán prestar, por sí o asociados, los municipios en atención a su población, y, para todos, declara los siguientes: alumbrado público, cementerio, recogida de residuos, limpieza viaria, abastecimiento domiciliario de agua potable, alcantarillado, acceso a los núcleos de población, pavimentación de las vías públicas y control de alimentos y bebidas.
}

Ninguno, seguramente, desconocemos municipios donde algunos de estos servicios no se prestan a los ciudadanos o, cuando menos, son prestados con deficiente calidad.

${ }^{4}$ No todos los autores, sin embargo, participan de esta idea. Así, R. Barranco Vela, Creación y supresión..., cit., p. 56, sitúa - no sin cierta razón- el origen o, mejor expresado, el impulso a la proliferación municipal en la Constitución de 1845, cuyo artículo 73 disponia que «habrá en los pueblos Alcaldes y Ayuntamientos». En la Ley de organización y atribuciones de los Ayuntamientos de 8 de enero de 1845 y en la precedente de 14 de julio de 1840 encuentra el autor citado el fundamento a la posterior dispersión municipal, ya que, entre otras cosas, hasta entonces - escribeno se puede hablar en propiedad de municipios.

${ }^{5}$ Para un conocimiento en profundidad de esta legislación remitimos a los trabajos de F. SosA WAGNeR Y P. DE MIGUEL GARCiA, Creación, supresión y alteración de términos municipales, IEAL, Madrid, 1987, pp. 15-55; C. Escun PALOP, «La alteración de términos municipales», Tratado de Derecho Municipal, I, dir. Santiago MuÑoz MaChado, Civitas, Madrid, 1988, pp. 1161-1169 y R. Barranco Vela, Creación y segregación..., cit., pp. 39-99. 
principio de conservación de los municipios existentes ${ }^{6}$ para regular, a continuación, la creación, supresión y lo que, tradicionalmente, se ha conocido con la denominación de alteración de términos municipales. No ha habido, pues - como han denunciado SOSA WAGNER y DE MIGUEL GARCíA $^{7}$-, una política propiamente dicha sobre esta materia, sino únicamente una serie de medidas concretas para hacer frente a las cuestiones que en este campo la realidad cotidiana presentaba en cada momento.

En la actualidad, la situación municipal en España sigue constituyendo un grave problema, si bien su intensidad es distinta según las diversas Comunidades Autónomas que integran nuestra nación.

Pese al acierto del constituyente de confiar esta materia, como tendremos ocasión de comprobar, a los nuevos Entes territoriales que se creaban, lo cierto es que las Comunidades Autónomas, con carácter general, en la legislación que sobre el particular han dictado no han abordado el problema o, mejor expresado, han efectuado una legislación «pro futuro», esto es, han mantenido la estructura territorial existente y han establecido requisitos más rigurosos o severos para la creación de nuevos municipios y la alteración de sus términos, pero nada más. En suma, han hecho muy poco -a mi juicio- para modificar la desastrosa estructura territorial municipal que, en algunos territorios, reviste caracteres de auténtico desastre.

Nos encontramos, como ha explicitado FERNÁNDEZ RODRÍGUEZ, ante la farsa de más de 8.000 Administraciones públicas ${ }^{8}$, ante «apariencias jurídicas sin sustancia social alguna», "ante municipios carentes de capacidad y sustantividad por sus escasas e ínfimas dimensiones» ${ }^{9}$, que no cumplen con la doble razón de ser de este tipo de Entidades: democrática, en tanto que son el cauce inmediato de participación de los ciudadanos y

\footnotetext{
${ }^{6}$ Así se expresaban, por sólo citar algunas, el Real Decreto de 23 de julio de 1835, para el arreglo provisional de los Ayuntamientos del Reino; las Leyes de organización y atribuciones de los Ayuntamientos de 1840 y 1845 o la Ley de Ayuntamientos de 5 de julio de 1856.

Sólo el Real Decreto de 21 de octubre de 1866 pretendió realmente la supresión de Ayuntamientos, al ordenarse que en un plazo de dos años deberían desaparecer todos los distritos municipales que no llegasen a 200 vecinos, dictándose, poco después, una Real Orden, que trató de poner en práctica este mandato.

${ }^{7}$ Creación, supresión..., cit., p. 41.

${ }^{8}$ T. R. FERnÁNDEZ RODRIGUEZ, Entre el Derecho y la política (escritos dispersos de un jurista independiente), Abella, Madrid, 1987, p. 23.

9 Son expresiones muy acertadas de A. FANLo LoRAS, «Estructura territorial», Anuario del Gobierno Local 1995, Diputació de Barcelona-Marcial Pons, Madrid, 1995, p. 176 y Anuario del Gobierno Local 1996, Diputació de Barcelona-Marcial Pons, Madrid, 1996, p: 241.
} 
precisamente en aquellos asuntos que más directamente conciernen a la vida diaria; y de eficacia administrativa, en tanto que son el ámbito de prestación de los servicios públicos condicionantes y determinantes de dicha calidad de vida. En definitiva, ante municipios en los que el principio de autonomía proclamado constitucionalmente no deja de ser una quimera irrealizable por la escasez de medios materiales y personales con que cuentan para cumplir las funciones que tienen encomendadas. La autonomía municipal, a pesar de su reconocimiento y garantía constitucional, sólo puede ser ejercitada $\longrightarrow$, si se quiere, disfrutada - por unos pocos municipios; a los demás, el «peso de la púrpura» no les permite sostenerse en pie.

Y, por último, manifestemos que éste seguirá siendo un grave problema y cada vez más acuciante de no adoptarse medidas extremas, de no llevarse a cabo una "cirugía municipal» de urgencia que suprima muchos de los municipios existentes, dado el despoblamiento que estamos sufriendo en los últimos años, si bien debemos advertir que quizás no sea ésta la única solución posible, aunque sí debe formar parte del paquete de medidas que reclamamos para atajar el problema planteado. Las diferencias entre los ciudadanos, según el municipio en que residan, se verán agrandadas, lo que incidirá en la calidad de vida de los pueblos. Por ello, la reforma de la estructura territorial municipal es urgente. Los poderes públicos deben adoptar soluciones convenientes para acabar con este mal endémico en la historia de nuestra Administración local.

No obstante, pongamos de relieve que el objeto de este estudio no es la "estructura territorial de España», si es que tales términos pueden emplearse ${ }^{10}$, sino, más concretamente, la de nuestra Comunidad Autónoma $\mathrm{y}$, si queremos precisar aún más, las normas que han pretendido o pretenden ofrecer algún atisbo de solución a la cuestión de la planta municipal. Por ello, es necesario que nos centremos en Castilla y León y en el ordenamiento jurídico emanado de sus instituciones de autogobierno.

\section{LA ESTRUCTURA TERRITORIAL MUNICIPAL DE CASTILLA Y LEÓN}

$\mathrm{Si}$, como hemos expuesto más arriba, la estructura territorial municipal en España es un problema grave, la situación de la planta municipal en

\footnotetext{
10 A. Fanlo Loras, en su trabajo «Estructura territorial», publicado en el Anuario del Gobierno Local 1995, cit., con acierto señala que «no puede hablarse genéricamente en este momento de la estructura territorial local en España, porque hoy la configuración exacta de la misma debe buscarse en las legitimas opciones que han hecho o están haciendo las Comunidades Autónomas», p. 175.
} 
Castilla y León constituye un problema, que no dudamos en calificar, de gravísimo, cuando no de catastrófico y, desde luego, alarmante.

Castilla y León, la región más extensa de cuantas integran la Europa comunitaria - por situarnos en un referente próximo- con una superficie de $94.193 \mathrm{Km}^{2}$, cuenta con algo menos de 2.500 .000 habitantes distribuidos en 2.248 municipios de manera muy desigual, como tendremos ocasión de comprobar. Es decir, tenemos el 27,8 por 100 de todos los municipios españoles, con tan sólo el 6,5 por 100 de la población.

La situación de la estructura municipal de esta Comunidad Autónoma ha sido descrita con precisión y sencillez por FERNÁNDEZ DE GATTA SÁNCHEZ y, por ello, seguiremos básicamente su exposición, si acaso aportando algún dato más ${ }^{11}$.

Dice este autor que tal situación se caracteriza por el gran número de municipios existentes, su dispersión geográfica y su escaso tamaño poblacional. A ello hay que añadir — sigue diciendo- la tendencia, hoy consolidada, a aumentar progresivamente las funciones y servicios obligatorios que deben prestar los municipios.

En efecto, de los poco más de 8.000 municipios con que cuenta España, Castilla y León, integrada por 2.248 municipios, ocupa, en lo que a número de municipios se refiere, el primer puesto de todas las Comunidades Autónomas y, también, el de Europa, lo que ya de por sí es un dato muy significativo. Pero es que, además - y aquí está la verdadera dimensión del problema-, el 86,81 por 100 de estos municipios tiene una población inferior de 1.000 habitantes, y hasta un 73,71 por 100 su población es menor de 500 habitantes. En cifras absolutas, debemos señalar que 1.957 municipios tienen menos de 1.000 habitantes $y$, recuérdese que la mayoria califica a los municipios de este tamaño poblacional de inframunicipios, y 1.657 tiene, aún, menos de 500 habitantes. Sólo 48 municipios tienen más de 5.000 habitantes, de los que 14 superan los 20.000 habitantes, debiendo tenerse presente que sólo estos 48 podrán ser sujetos receptores de competencias transferidas o delegadas por la Comunidad Autónoma ${ }^{12}$. Y, por último, pongamos de relieve que sólo son 4 los mu-

\footnotetext{
11 Nos referimos a su trabajo «Los problemas de la estructura municipal de Castilla y León: instrumentos y soluciones de la nueva Ley de Régimen Local", El Consultor, n. ${ }^{\circ} 19,1999$, pp. 2248 y 2249.

${ }^{12}$ La Ley 6/1986, de 6 de junio, Reguladora de las Relaciones entre la Comunidad de Castilla y León y las Entidades Locales, establecía que sólo podían ser sujetos receptores de transferencia o delegación de competencias de la Comunidad Autónoma las Diputaciones Provinciales y los Ayuntamientos de más de 20.000 habitantes (art. 5.1). Ahora, por lo que respecta a los Ayuntamientos, la
} 
nicipios castellanos y leoneses que superan los 100.000 habitantes: Burgos, León, Salamanca y Valladolid. Castilla y León, podemos afirmar, está integrada de manera muy mayoritaria por inframunicipios, esto es, entes carentes de capacidad y sustantividad en los que los principios constitucionales de autonomía y suficiencia financiera están bastante alejados de la realidad ${ }^{13}$.

La situación real de los municipios de Castilla y León en cuanto a su tamaño poblacional puede verse en el cuadro de la página siguiente:

Esta Comunidad Autónoma, además, tiene una población dispersa, en general, si bien su mayoría se encuentra en los 48 municipios que cuentan con más de 5.000 habitantes. En éstos residen 1.440.546 habitantes; de los 2.484.926 habitantes que, según la renovación del padrón municipal de habitantes de 1998, dispone Castilla y León; viviendo 780.196 personas en los 4 municipios con más de 100.000 habitantes y 541.079 personas en los municipios de menos de 1.000 habitantes ${ }^{14}$.

Ésta es una situación municipal, además, estabilizada desde el punto de vista jurídico-administrativo, tras la reducción de municipios que tuvo lugar en los años 1960-1980.

En Castilla y León se encuentran en la actualidad - como muy bien señala FERNÁNDEZ DE GATTA ${ }^{15}$ - dos tendencias: por un lado, la existencia de muchos municipios con escasa población, es decir, una fragmentación impresionante $\mathrm{o}$, si se quiere, una atomización municipal sólo comparable, en Europa, a la de Francia; y, por otro, una fuerte concentración de la población en municipios mayores de 5.000 habitantes.

\footnotetext{
nueva Ley de Régimen Local ha rebajado este requisito poblacional a los 5.000 habitantes y, además, también ha incluido entre estos sujetos receptores de competencias autonómicas transferidas o delegadas a los municipios que cuenten con servicios culturales, educativos, sanitarios, sociales, administrativos o de otra naturaleza mediante los cuales se satisgafa la demanda de los residentes en otros municipios limitrofes, siempre que tengan capacidad de gestión (art. 84.1).

${ }_{13}$ De «verdaderas Administraciones fantasmas», vaciados de sus funciones públicas esenciales, manteniendo una apariencia exterior respetada por la legislación vigente, ha calificado a muchos municipios de nuestra Comunidad un Consejero de Presidencia y Administración Territorial de la Junta de Castilla y León. Vid. I. LOPEZ ANDUEZA, «Mancomunidades de municipios, servicios públicos y organización del territorio", I Seminario Iberoamericano sobre Mancomunidades Municipales, Junta de Castilla y León, Consejería de Presidencia y Administración Territorial, Segovia, 1997, p. 146.

14 Tomo los datos de Anuario Estadistico de Castilla y León 2000, Consejería de Economía y Hacienda de la Junta de Castilla y León, Valladolid, 2000, p. 37.
}

15 «Los problemas de la estructura...», cit., p. 2249. 


\begin{tabular}{|c|c|c|c|c|c|c|c|c|c|c|c|c|c|c|c|}
\hline & \multicolumn{2}{|c|}{$\begin{array}{l}\text { Municipios } \\
\text { hasta } 100 \\
\text { habitantes }\end{array}$} & \multicolumn{2}{|c|}{$\begin{array}{c}\text { Municipios } \\
101-250 \\
\text { habitantes }\end{array}$} & \multicolumn{2}{|c|}{$\begin{array}{l}\text { Municipios } \\
251-500 \\
\text { habitantes }\end{array}$} & \multicolumn{2}{|c|}{$\begin{array}{l}\text { Municipios } \\
501-1.000 \\
\text { habitantes }\end{array}$} & \multicolumn{2}{|c|}{$\begin{array}{c}\text { Municipios } \\
1.001-2.000 \\
\text { habitantes }\end{array}$} & \multicolumn{2}{|c|}{$\begin{array}{c}\text { Municipios } \\
2.001-5.000 \\
\text { habitantes }\end{array}$} & \multicolumn{2}{|c|}{$\begin{array}{l}\text { Municipios } \\
+5.000 \\
\text { habitantes }\end{array}$} & \multirow[t]{2}{*}{ TOTAL } \\
\hline & $\mathrm{N} .^{\circ}$ & $\%$ & $\mathrm{~N} .^{\circ}$ & $\%$ & $\mathrm{~N} .^{\circ}$ & $\%$ & N. ${ }^{\circ}$ & $\%$ & N..$^{\circ}$ & $\%$ & $\mathrm{~N}^{\circ}$ & $\%$ & N. ${ }^{\circ}$ & $\%$ & \\
\hline ÁVILA. & 37 & 14,9 & 107 & 43,1 & 51 & 20,5 & 28 & 11,2 & 10 & 4 & 11 & 4,4 & 4 & 1,6 & 248 \\
\hline BURGOS. & 121 & 32,6 & 137 & 36,9 & 52 & 14 & 38 & 10,2 & 8 & 2,1 & 10 & 2,6 & 5 & 1,3 & 371 \\
\hline LEÓN. ... & 1 & 0,4 & 20 & 9,4 & 45 & 21,3 & 56 & 26,5 & 54 & 25,5 & 24 & 11,3 & 11 & 5,2 & 211 \\
\hline SEGOVIA. . . & 55 & 26,3 & 72 & 34,5 & 38 & 18,1 & 23 & 11 & 13 & 6,2 & 4 & 1,9 & 4 & 1,9 & 209 \\
\hline SORIA. . . & 86 & 46,9 & 50 & 27,3 & 27 & 14,7 & 8 & 4,3 & 4 & 2,1 & 5 & 2,7 & 3 & 1,6 & 183 \\
\hline VALLADOLID. & 37 & 16,4 & 73 & 32,4 & 50 & 22,2 & 26 & 11,5 & 21 & 9,3 & 10 & 4,4 & 8 & 3,5 & 225 \\
\hline ZAMORA. . & 6 & 2,4 & 63 & 25,4 & 95 & 38,3 & 57 & 22,9 & 24 & 9,6 & - & - & 3 & 1,2 & 248 \\
\hline CASTILLA Y LEÓN. . . & 419 & 18,6 & 719 & 31,9 & 519 & 23 & 300 & 13,3 & 156 & 7,3 & 77 & 3,4 & 48 & 2,1 & 2.248 \\
\hline
\end{tabular}

Fuente: Dirección General de Administración Territorial.

Consejería de Presidencia y Administración Territorial. 
A los datos precedentes, debemos añadir que nuestra Comunidad $\mathrm{Au}-$ tónoma es, también, la que cuenta con mayor número de Entidades de ámbito inferior al municipio de toda España. De las 3.724 Entidades de ámbito territorial inferior al municipal que, según el censo de Entidades Locales de mayo de 1995, existen en nuestra nación, 2.230 están ubicadas en Castilla y León, concentrándose la mayor parte de ellas (1.241) en la provincia de León.

Por provincias la distribución de Entidades Locales Menores que existen en Castilla y León es la siguiente:

\begin{tabular}{|l|r|}
\hline ÁVILA: & 2 \\
BURGOS: & 649 \\
LEÓN: & 1.241 \\
PALENCIA: & 228 \\
SALAMANCA: & 19 \\
SEGOVIA: & 13 \\
SORIA: & 56 \\
VALLADOLID: & 9 \\
ZAMORA: & 13 \\
\hline TOTAL: & 2.230 \\
\hline
\end{tabular}

En el siguiente cuadro exponemos el número de este tipo de Entidades por provincias y su población tanto absoluta como en términos porcentuales:

El gran número de municipios existentes, su dispersión geográfica, su escasa población y su clara regresión económica, junto a la disminución y envejecimiento de la población ${ }^{16}$, traen consigo que tales municipios no puedan, en la práctica, prestar y cumplir los servicios obligatorios que tienen encomendados, es decir, no puedan autogobernar sus propios intereses.

El legislador castellano y leonés, plenamente consciente de esta situación, la ha descrito con mayor autoridad que la de cualquier autor, en la

\footnotetext{
${ }_{16}$ Por ofrecer sólo un dato que prueba la afirmación que realizamos, de 2.577.105 habitantes según el censo de población de 1981 hemos pasado a tener, según el censo de 1996, 2.508.496 habitantes, esto es, una variación absoluta de -37.351 habitantes.

En cuanto al envejecimiento de la población nos remitimos al Anuario Estadistico..., cit., pp. 40-42.

Vid., también, R. Montoro Romero y R. Jiménez Abortiz, «Población y demografia», Papeles de Economia Española. Economia de las Comunidades Autónomas. Castilla y León, n. ${ }^{\circ} 14,1994$, pp. 131-147.
} 


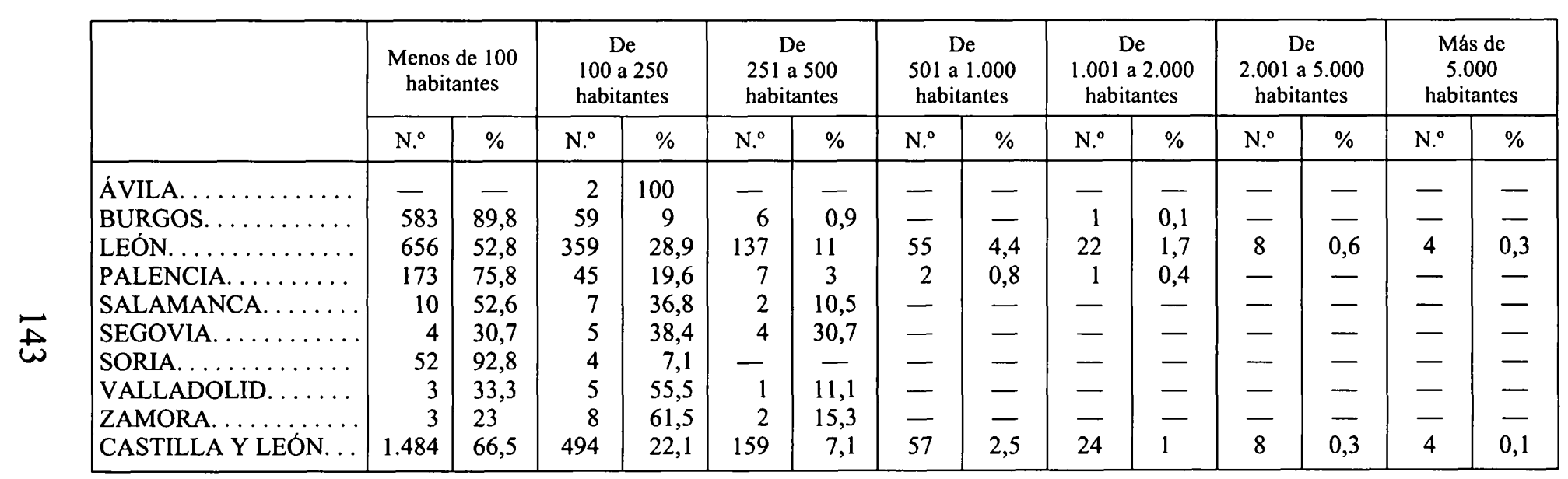

Fuente: Dirección General de Administración Territorial.

Consejería de Presidencia y Administración Territorial. 
Exposición de Motivos de la Ley 1/1998, de 4 de junio, de Régimen Local de Castilla y León ( $B O C y L$ de 11 de junio). Pese a la extensión del texto, no nos resistimos a su reproducción completa en estas páginas por la lucidez con que lo ha hecho:

«... La Ley afronta, en primer lugar, el aspecto relativo a las estructuras municipales, sin duda el más problemático, pues no puede olvidarse que Castilla y León es una Comunidad con una población de derecho algo superior a 2.500.000 habitantes que se distribuye de forma muy desigual a lo largo de su geografia. Esta población que representa aproximadamente el 6,5 por 100 de la población de la total del Estado se distribuye en 2.247 municipios que, a su vez, representan el 27,8 por 100 del total de municipios de la nación. Por otra parte, del total de municipios de la Comunidad Autónoma sólo 47-2,09 por 100-disponen de una población de derecho superior a los 5.000 habitantes y el 86,27 por 100 cuenta con menos de 1.000 habitantes de los cuales 1.051 no superan los 250 .

Los anteriores datos son reveladores de la grave situación municipal en la Comunidad, que se manifiesta, fundamentalmente, a través del gran número de municipios existentes, su dispersión geográfica, y, demográficamente, de escaso tamaño, asi como en clara regresión económica y administrativa.

Este declive de una densa y dilatada historia municipal ha convertido a Castilla y León, en el ámbito rural, en un amplio territorio despoblado en el que más que asentarse sobreviven minúsculos núcleos de población con un gradual proceso de disminución y envejecimiento. La mayoria de estos núcleos, aunque conservan su condición de municipios son incapaces, por carecer de medios personales y materiales, de autogobernar sus intereses, resultando inviables desde la perspectiva de una satisfacción racional y moderna de sus propias necesidades colectivas que constituye la justificación formal y material de su existencia institucional.

En resumen, la amplitud de competencias frente a la escasez de recursos, hace estéril el principio constitucional de autonomía municipal al no contar muchas Entidades locales con otros medios financieros que las ayudas de otras Administraciones Públicas.»

Ante tan precisa descripción, la consecuencia obligada tendría que haber sido la adopción de las medidas necesarias para realizar un cambio radical, pero, como veremos, no ha ocurrido así; a lo más que se ha llegado es a establecer un bosquejo de lo que podría hacerse en esta materia. 


\section{COMPETENCIAS DE CASTILLA Y LEÓN SOBRE LA ESTRUCTURA TERRITORIAL LOCAL}

Castilla y León, como el resto de Comunidades Autónomas que accedieron a la autonomía por la vía del artículo 143 de la Constitución, no asumió en su «norma institucional básica» competencias en materia de Régimen Local así expresado. Tampoco lo hizo, transcurridos los cinco años a que hace referencia el artículo 148.2 del texto constitucional, $y$, después de la celebración de los Acuerdos Autonómicos de 28 de febrero de 1992, a través de la Ley Orgánica 9/1992, de 23 de diciembre, de Transferencia de competencias a las Comunidades Autónomas que accedieron a la autonomía por la vía del artículo 143 de la Constitución, que sirvió para la aplicación de los citados Acuerdos, ni la posterior reforma del Estatuto de Autonomía llevada a cabo mediante la Ley Orgánica $11 / 1994$, de 24 de marzo ${ }^{17}$.

La asunción de competencias sobre esta materia no se ha producido sino hasta la última reforma estatutaria operada en virtud de la Ley Orgánica 4/1999, de 8 de enero, de reforma de la Ley Orgánica 4/1983, del Estatuto de Autonomía de Castilla y León, y, así, a tenor de lo dispuesto en el artículo 34.3 de éste, la Comunidad Autónoma de Castilla y León, ahora, dispone de competencias de desarrollo normativo y de ejecución en materia de Régimen Local.

Esto no significa, no obstante, que Castilla y León no dispusiera, desde el principio, de competencia alguna en la materia objeto del presente trabajo, esto es, competencias que pudieran incidir sobre la estructura territorial municipal.

Como hemos señalado más arriba, el constituyente de 1978 tuvo el acierto de confiar esta materia a las Comunidades Autónomas, al señalar en el artículo 148.1.2. a que éstas podrían asumir competencias sobre «las alteraciones de los términos municipales comprendidos en su territorio y, en general, las funciones que correspondan a la Administración del Estado sobre las Corporaciones locales y cuya transferencia autorice la legislación sobre Régimen Local». Pues bien, las Comunidades Autónomas asumieron en sus respectivos Estatutos de Autonomía esta materia y Castilla y León, en concreto, la asumió entre las competencias de desarrollo

\footnotetext{
17 Sobre estas cuestiones, véase A. Calonge Velázquez, J. A. Garcta de Coca, y J. Arroyo Dominguez, «Estudio introductorio», Estatuto de Autonomia de Castilla y León. Trabajos Parlamentarios, Cortes de Castilla y León, Valladolid, 1998, pp. XXXIV-XLIX.
} 
normativo y ejecución al disponer el artículo 27.8. de su Estatuto de Autonomía que «En el marco de la legislación básica del Estado y, en su caso, en los términos que la misma establezca, es competencia de la Comunidad de Castilla y León el desarrollo y ejecución de la legislación del Estado en las siguientes materias... Alteraciones de términos municipales y las que correspondan a la Administración del Estado sobre las Corporaciones Locales cuya transferencia autorice la legislación sobre régimen local». La Constitución, primero, y los Estatutos de Autonomía, después, permiten, pues, responsabilizarse a las Comunidades Autónomas en gran medida del proceso de reforma y modernización de las estructuras de la organización territorial.

Pero, téngase bien presente que esta competencia sobre la materia «alteración de los términos municipales» $\mathrm{y}$, ahora, el «Régimen Local» está entre las de desarrollo normativo y ejecución, pues al Estado le corresponde, según dispone el artículo 149.1.18. ${ }^{a}$ de la Norma fundamental, el dictado de las bases del régimen jurídico de las Administraciones públicas, entre las que, claro está, se encuentra la Administración municipal. La distribución de competencias que sobre el régimen local contiene la Constitución se realiza mediante un diferente protagonismo normativo del Estado y de las Comunidades Autónomas, atribuyendo al primero la determinación de las bases de aquél y a las segundas el desarrollo de éstas ${ }^{18}$. Se trata, pues, de una competencia concurrente sobre la que puede incidir tanto el Estado como las Comunidades Autónomas.

Pues bien, el Estado, en virtud de la competencia señalada - atribuida ex costitutione-, promulgó, como es sabido, la Ley 7/1985, de 2 de abril, Reguladora de las Bases del Régimen Local, conteniendo un precepto —l art. 13-que disciplina la materia que tratamos, añadiendo, además de las competencias que las Comunidades Autónomas ya tenían en materia de alteración de términos municipales, la de regular la creación y supresión de municipios, con lo que esta materia, como han señalado SoSA WAGNER y DE Miguel GaRCía ${ }^{19}$, va a ser de la plena disponibilidad de las Comunidades Autónomas, que sólo se encontrarán vinculadas por los criterios materiales que incorpora el mencionado precepto y por los trámites procedimentales que contiene. Todo ello por el carácter básico que la Ley tiene en su integridad.

\footnotetext{
$18 \mathrm{Vid}$. un interesante estudio sobre las competencias de las Comunidades Autónomas en relación a la Administración local en M. SÁNCHEZ MORÓN, «La distribución de competencias entre el Estado y las Comunidades Autónomas en materia de Administración Local», Tratado..., cit., pp.

19 F. Sosa Wagner y P. de Miguel Garcta, Creación, supresión..., cit., p. 67.
} 
En definitiva, a las Comunidades Autónomas les ha correspondido, desde el primer momento, la creación y supresión de municipios, las alteraciones de los términos municipales y lo relativo a las estructuras supra $\mathrm{e}$ inframunicipales; reservándose el Estado la regulación que con carácter necesario deben reunir los municipios $\mathrm{y}$, por lo tanto, las condiciones imprescindibles para la creación y modificación de municipios, así como la regulación del procedimiento administrativo básico para llevar a cabo tales operaciones.

Castilla y León tiene, pues, plena disponibilidad sobre su estructura territorial local, lo que, como ya hemos explicitado, nos parece un acierto, para que, desde su conocimiento de la realidad más inmediata y dentro del respeto a los criterios básicos establecidos por el legislador estatal, pueda adoptar las decisiones más adecuadas a sus necesidades, es decir, configurar una estructura territorial local apropiada, idónea a las necesidades de esta tierra.

\section{LAS NORMAS CASTELLANO Y LEONESAS SOBRE LA ESTRUCTURA MUNICIPAL}

Cualquier analista o mero observador de la realidad municipal de Castilla y León no precisaría de mucho tiempo para llegar a la conclusión de que es necesario un cambio radical del panorama descrito y, consecuentemente, solicitar la adopción de medidas extremas que lleven a una modificación completa de la estructura municipal castellano y leonesa.

Las instituciones de autogobierno de la Comunidad Autónoma de Castilla y León, pese a ser plenamente conscientes de la necesidad de llevar a cabo - si se me permite la expresión - una «revolución» en la planta municipal, no han adoptado, en mi opinión, las medidas necesarias para que ésta pueda darse o, expresado en otros términos, incidir de forma determinante en la paupérrima o penosa situación de los municipios castellanos y leoneses.

Tempranamente -como tendremos ocasión de comprobar - la Junta de Castilla y León tuvo muy presente el problema y dictó, tratando de paliarlo y de acuerdo con lo que propugna un importante sector doctrinal ${ }^{20}$, una norma de carácter general que tenía por objeto el fomento de las man-

\footnotetext{
${ }^{20}$ En este sentido, vid., por todos, L. Morell Ocaña, «El asociacionismo local en Europa», Primera Asamblea de Mancomunidades de Castilla y León, Junta de Castilla y León, Consejería de Presidencia y Administración Territorial, Valladolid, 1987, pp. 15-39.
} 
comunidades municipales, constituyendo, prácticamente, durante algún tiempo la única norma en materia local dictada por la Comunidad Autónoma ${ }^{21}$.

No será sino hasta hace pocas fechas cuando las Cortes de Castilla y León aprueben una Ley de Régimen Local, que, entre otras cuestiones, establecerá algunas medidas tendentes a la modificación de la estructura territorial municipal de Castilla y León, regulando, como veremos, la creación y supresión de los municipios, la alteración de términos municipales, así como las Entidades supra e inframunicipales, entre otras cuestiones.

Las dos normas enunciadas son las únicas que, en los más de quince años de existencia de esta Comunidad Autónoma, Junta y Cortes de Castilla y León han dictado con la pretensión de incidir en la planta municipal. Además, debe tenerse presente también un Proyecto de Ley Municipal de Castilla y León antecedente de la vigente norma reguladora de la Administración local castellano y leonesa.

A estas normas nos vamos a referir en las páginas que siguen.

\section{El Decreto para el fomento de las Mancomunidades Municipales}

Como hemos señalado, muy pronto la Junta de Castilla y León tuvo conciencia del problema que suponía la planta municipal de la Comunidad Autónoma y, por ello, dictó, a poco más de un año de su constitución, el Decreto 110/1984, de 27 de septiembre, para el fomento de las Mancomunidades Municipales (BOCyL de 1 de octubre) ${ }^{22}$. Con esta disposi-

\footnotetext{
${ }^{21}$ En el año 1986 y en desarrollo del artículo 20 del Estatuto de Autonomía se dictó la Ley 6/1986, de 6 de junio, reguladora de las relaciones entre la Comunidad Autónoma y las Entidades Locales. Y en 1991, al amparo del artículo 19,3 de la norma institucional básica de la Comunidad Autónoma, que prevé la posibilidad de crear las comarcas, como nueva Administración intercalada entre la provincia y el municipio, se dictó la Ley $1 / 1991$, de 14 de marzo, por la que se crea y regula la Comarca de El Bierzo, única que existe en nuestra Comunidad Autónoma, fruto del compromiso electoral asumido por la fuerza política que, a la postre, resultaría ganadora en las elecciones autonómicas de 1987, con el que se pretendia dar satisfacción a una demanda fuertemente sentida en el territorio berciano.
}

Sobre la primera de las Leyes citadas, vid. A. Calonge Velázquez, T. González del Teso y J. A. GARCIA DE COCA, Autonomias y Municipios. Descentralización y coordinación de competencias, Secretariado de Publicaciones de la Universidad de Valladolid, Valladolid, 1995.

Sobre la Ley de creación de la Comarca de El Bierzo, vid. T. QuINTANA LóPEZ, «Las comarcas en Castilla y León. La comarca del Bierzo», RAAP, n. ${ }^{\circ} 3,1993$, pp. 139-152.

${ }^{22}$ La asociación de varios municipios para la realización de obras y servicios de interés común, dando lugar a la creación de una Entidad local, empieza en Castilla y León en 1969. El 13 de marzo 
ción, debe observarse, la Comunidad de Castilla y León se adelantó a numerosas Comunidades en la regulación y fomento de las Mancomunidades Municipales.

El Consejo de Gobierno de esta Comunidad Autónoma en el preámbulo de esta disposición general reconocía - con gran acierto- que «uno de los mayores problemas que la afectan lo constituye la existencia de un elevado número de municipios, situación que se ve agravada por la escasa capacidad de movilizar recursos propios o recibir ajenos, lo que dificulta gravemente la prestación de los servicios mínimos a que todo ciudadano tiene derecho».

En la búsqueda de soluciones que, respetando al máximo la autonomía municipal, paliaran esta situación, la Junta de Castilla y León se inclinaba por las fórmulas asociativas voluntarias, fomentando la creación de mancomunidades y estableciendo y regulando la concesión a las mismas de cuantas ayudas técnicas y económicas se estimen necesarias, a fin de conseguir una máxima eficacia administrativa y una óptima prestación de servicios, lo que redundará en una más alta calidad de vida de los pueblos.

En realidad, este Decreto no sólo regulaba el fomento de estos entes asociativos municipales, aunque éste era su objeto expresamente declarado, sino que iba más allá. El propio título del proyecto de Decreto que la Junta de Castilla y León remitió a la consulta del Consejo de Estado - «constitución y funcionamiento de las Mancomunidades Municipales»- así lo atestigua, pero, desde luego, mucho más su contenido material.

La norma examinada está estructurada en veintiocho artículos distribuidos en ocho capítulos, más tres disposiciones finales, en la que pueden encontrarse, al menos, cuatro tipos de normas, aquéllas que, como los artículos 1 y 3 , reproducen, prácticamente, preceptos de la Ley que desarrolla ${ }^{23}$; aquellas que, integradas en el capítulo II (arts. 4, 5 y 6), están dedicadas a las medidas de fomento de las mancomunidades; aquellos otros, que cons-

de 1969, se constituyó la Mancomunidad de «La Comarca de Ponferrada», cuyo fin básico era el abastecimiento de agua a la población. Incorporaba a 8 municipios, beneficiando alrededor de 72.000 habitantes. En la década de los setenta fueron muy pocas las Mancomunidades que se constituyeron, tan sólo se crearon 5 , de las cuales cuatro tenian como finalidad el abastecimiento de agua (es el caso de «Aguas del Carrión», «Villas de Tierra de Campos», «Aguas Baltanás-Villaviudas», «Aguas de Azud de Villagonzalo de Tormes).

${ }^{23}$ El Decreto se dictó en desarrollo del Real Decreto 3046/1977, que articuló parcialmente la Ley 41/1975, de Bases del Régimen Local. Después, lógicamente, este Decreto se vio afectado por toda la normativa estatal surgida con posterioridad. 
tituyen la mayor parte del Decreto, que introducen un régimen orgánico y funcional muy detallado y uniforme para las mancomunidades (arts. 7 a 25); y, finalmente, los artículos 27 y 28 que constituyen el capítulo VIII, y que establecen las normas para la tramitación y aprobación de las mancomunidades y sus Estatutos por la propia Junta de Castilla y León.

Así pues, y como fácilmente se observa, el Ejecutivo castellano y leonés no se limitó al establecimiento de medidas de fomento de las Mancomunidades municipales, sino que hizo un desarrollo completo de este tipo de entidades supramunicipales que, por una parte, chocaba con el principio de autonomía municipal y, por otra, invadía las competencias del Estado, según ponía de relieve con toda claridad el dictamen del Consejo de Estado.

Así es. El régimen orgánico y funcional de las Mancomunidades municipales regulado en este Decreto, que, además, según establece su artículo 2, forma parte del contenido obligatorio de los Estatutos de las mancomunidades que se crearan, es poco compatible con el principio de autonomía municipal, pues introduce una norma interpuesta entre las condiciones mínimas legalmente exigidas y la voluntad intermunicipal que se plasma en los Estatutos. Y, además, invade las competencias estatales, ya que entra a regular la composición y funcionamiento de los órganos de estos entes, interfiriendo de este modo el régimen jurídico de las Administraciones públicas, que, como es sabido, es competencia exclusiva del Estado.

Es decir, que el contenido de los artículos 7 y siguientes del Decreto, al imponer - por relación con el artículo 2- una determinada y homogénea organización a las Mancomunidades municipales, está limitando las posibilidades estatutarias que permitirian a estos municipios, en cada caso, y con respeto simplemente de la legislación general, adoptar la organización que les parezca más conveniente y adecuada a sus peculiaridades.

Y esta interferencia con la autonomía organizativa de los municipios en esta cuestión se hace también entrando en materias que sólo al Estado competen por virtud del artículo 149.1.18. ${ }^{a}$ de la Constitución; tal ocurre, por ejemplo, con el régimen de acuerdos del artículo 16 , así como con algunos preceptos reguladores de los órganos de gobierno y administración de este tipo de Entidades que, no sólo invadirían la competencia estatal por consecuencia del argumento señalado, sino que, además, podría entenderse que también interfieren la exclusiva competencia del Estado en materia de elecciones locales.

Por otro lado, resulta también, cuando menos, extraño la regulación que se hace en el apartado 2 del artículo 22 relativa a la separación forzo- 
sa de la Mancomunidad de alguno de los municipios integrados, por grave incumplimiento de las obligaciones establecidas en las Leyes o en los Estatutos, que será acordada por el voto favorable de los dos tercios del Consejo de la Mancomunidad y aprobada por la Junta de Castilla y León.

Ahora bien, a tenor de diversas dudas interpretativas que planteaba el alcance de esta separación, la Junta de Castilla y León entendió aconsejable que fueran los propios municipios que pretendieran mancomunarse los que establecieran en sus Estatutos cláusulas de garantía del buen funcionamiento de la Mancomunidad y, por ello, en virtud del Decreto 134/1984, de 21 de diciembre (BOCyL de 2 de enero de 1985), se suprimió el número 2 del artículo 23 del Decreto que estamos analizando.

A las medidas para el fomento de las Mancomunidades municipales, realmente, sólo se dedican tres preceptos, y que se concretan, de una parte, en la asistencia técnica y jurídica que prestará la Junta de Castilla y León, a través de la Consejería de Presidencia y Administración Territorial, para la constitución y funcionamiento de una Mancomunidad, y siempre que sea solicitada por los municipios que pretendan mancomunarse o por la propia Mancomunidad y, de otra parte, en una serie de ayudas previstas genéricamente en el artículo 5, al disponer que la Junta de Castilla y León, a través de la Consejería de Presidencia y Administración Territorial, consignará en el Proyecto de Presupuestos una partida destinada al fomento y ayuda de las Mancomunidades municipales. Dichas ayudas podrán concederse directamente a las Mancomunidades constituidas o municipios en proceso de mancomunarse y también a las Diputaciones provinciales, cuando éstas lo soliciten por haber aprobado un plan concreto de fomento de Mancomunidades en la provincia.

No obstante el contenido material de esta norma y los problemas jurídicos que plantea, lo cierto es que tras la publicación de este Decreto la cooperación intermunicipal a través de la creación de Mancomunidades experimentó un gran desarrollo y, de esta manera, de las 6 Mancomunidades que existían a finales de 1983 hemos pasado a tener 200, de las cuales 10 son interprovinciales, que agrupan a 1.837 municipios, lo que representa el 81,72 por 100 , y que integran a 1.634 .425 habitantes, esto es, el 65,78 por 100 de la población castellano y leonesa ${ }^{24}$.

\footnotetext{
${ }^{24}$ Apenas dos años después de la promulgación del referido Decreto, difundida y conocida la posibilidad, rota la barrera de la falta de apoyo, se constituyeron treinta y una nuevas Mancomunidades.

Vid. una exposición de los logros de esta disposición en V. Merino Estrada, «Las Mancomunidades en Castilla y León», Primera Asamblea...., cit., pp. 5-13 y I. LÓPEZ ANDUEZA, «Mancomunidades de Municipios...», cit., pp. 153-155.
} 
La distribución de Mancomunidades por provincias es la expresada en el cuadro siguiente:

\begin{tabular}{|c|c|c|}
\hline \multirow{2}{*}{ PROVINCIAS } & \multicolumn{2}{|c|}{ MANCOMUNIDADES } \\
\hline & N. ${ }^{\circ}$ & $\%$ \\
\hline$\ldots \ldots \ldots \ldots \ldots \ldots \ldots$ & 24 & 12 \\
\hline BURGOS $\ldots \ldots \ldots \ldots \ldots \ldots$ & 26 & 13 \\
\hline LEÓN $\ldots \ldots \ldots \ldots \ldots \ldots \ldots \ldots$ & 36 & 18 \\
\hline PALENCIA ... & 20 & 10 \\
\hline SALAMANCA . . . . . . . . & 28 & 14 \\
\hline SEGOVIA $\ldots \ldots \ldots$ & 19 & 9,5 \\
\hline SORIA $\ldots \ldots \ldots$ & 8 & 4 \\
\hline VALLADOLID $\ldots \ldots \ldots \ldots$ & 14 & 7 \\
\hline 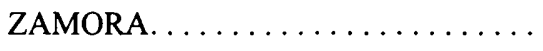 & 15 & 7,5 \\
\hline$\ldots \ldots \ldots \ldots$ & $\begin{array}{c}190+10 \\
\text { (interprovinciales) }\end{array}$ & \\
\hline
\end{tabular}

Fuente: Dirección General de Administración Territorial.

Consejería de Presidencia y Administración Territorial.

La política de fomento de las Mancomunidades se articuló de manera específica, primero, en el Decreto 118/1984, de 25 de octubre, por el que se regula la cooperación de la Junta de Castilla y León con las Entidades Locales, que disponía la concesión de ayudas económicas para gastos de inversión de hasta un 70 por 100 del total de la obra, suministro o actividad de que se trate e, incluso, excepcionalmente, la Junta de Castilla y León, a propuesta de la Consejería respectiva, podría autorizar un porcentaje superior al anteriormente establecido, esto es, podría llegar a financiar la totalidad de la obra, suministro o actividad. Después, tras la promulgación de la Ley 6/1986, de 6 de junio, de Relaciones de la Comunidad de Castilla y León con las Entidades locales, que creaba el Fondo de Cooperación Local, a través de diversos Decretos ${ }^{25}$, el último de los cuales es el Decreto 57/1990, de 5 de abril, regulador de la Gestión del

\footnotetext{
${ }^{25}$ Véanse los Decretos 7/1987, de 15 de enero, por el que se regula la gestión del Fondo de Cooperación Local de la Comunidad de Castilla y León para 1987; 36/1988, de 25 de febrero, por el que se regula la gestión del Fondo de Cooperación Local de la Comunidad de Castilla y León y 108/1989, de 31 de mayo, regulador del Fondo de Cooperación Local de la Comunidad de Castilla y León.

Véanse, también, los Acuerdos de la Junta de Castilla y León, por los que se conceden ayudas económicas para la realización de proyectos de inversión, a diversas Mancomunidades Municipales, que constituyen aplicación de los Decretos citados, de 18 de julio de 1985 (BOCyL de 23 de julio), de 30 de mayo de 1986 ( $B O C y L$ de 9 de julio) y de 14 de mayo de 1987 (BOCyL de 25 de mayo).
} 
Fondo de Cooperación Local, cuyo Título IV se dedica a las ayudas a las Mancomunidades municipales.

Esta norma establece una línea de ayudas dirigida a la realización de inversiones en obras y servicios, pudiendo llegar al 70 por 100 del coste del proyecto y excepcionalmente al 90 por 100 , para lo cual la Junta de Castilla y León realiza todos los años una convocatoria específica.

De las cantidades presupuestadas alrededor del 70 por 100 se destina a la financiación de obras y servicios relacionados con la recogida de residuos sólidos y el 10 por 100 con el servicio de abastecimiento de agua.

Además de este programa específico, las Mancomunidades gozan de prioridades en programas sectoriales de los departamentos de la Junta, así convocatoria de ayudas para la conservación y mejora de las infraestructuras viarias o para la transformación y mejoras de los terrenos comunales y de propios.

El Decreto expuesto ha sido, finalmente, derogado de manera expresa en virtud de la cláusula derogatoria de la Ley de Régimen Local de Castilla y León.

\section{El Proyecto de Ley Municipal de Castilla y León}

El Boletín Oficial de las Cortes de Castilla y León n. ${ }^{\circ} 230$, de 15 de febrero de 1995, publicaba el primer intento de regulación de la estructura territorial municipal de la Comunidad Autónoma. En la citada publicación aparecía el Proyecto de Ley Municipal de Castilla y León, remitido pocos días antes por el Gobierno autonómico, que, sin embargo, no llegará a ver la luz en las páginas del Boletín Oficial de Castilla y León, ya que, al poco de ser presentado y tras no obtener el consenso necesario - $a$ juicio de la Junta de Castilla y León- entre los grupos parlamentarios ${ }^{26}$,

\footnotetext{
${ }^{26}$ El grupo parlamentario socialista presentó una enmienda a la totalidad solicitando la devolución del texto a la Junta de Castilla y León, ya que, en su opinión, no abordaba las principales necesidades de la ordenación de la vida municipal: ni el régimen de competencias, ni la descentralización, ni la transferencia de medios y servicios, ni la objetivización de los apoyos económicos y técnicos a las entidades locales, ni las relaciones entre el medio rural y urbano. Además, aquellos aspectos tratados, como el régimen de fusiones y creación de municipios y mancomunidades, lo estaban con una óptica conservadora y burocrática. Vid. Boletin Oficial de las Cortes de Castilla y León, III Legislatura, n. ${ }^{\circ} 241$, de 23 de marzo de 1995, pp. 13092-13093.
}

También el grupo parlamentario mixto, a propuesta del Procurador de Izquierda Unida, presentó una enmienda a la totalidad, justificada en que el Proyecto de Ley vulneraba criterios y derechos históricos, negándose a interpretar positivamente los existentes a fin de que una adecuada ordenación del territorio compense las deficiencias y carencias que vive Castilla y León. Vid. Boletín Oficial..., cit., p. 13094. 
ésta decidió retirarlo el mismo día de su presentación, el 30 de marzo de $1995^{27}$.

Traemos a colación este texto, aunque no haya sido promulgado ni, en consecuencia, haya podido ser objeto de aplicación, porque, en primer término, constituye el único antecedente existente de la vigente Ley de Régimen Local y, en segundo lugar, porque muchos de sus contenidos se verán reflejados en la Ley vigente; así sucede con buena parte de su Exposición de Motivos y con diversas materias que regula, verbi gratia, las relativas a la creación, supresión y alteraciones parciales de términos municipales, las Mancomunidades municipales o las Entidades de ámbito inframunicipal.

El Proyecto de Ley presentado se asentaba sobre las competencias que, en materia de alteración de términos municipales y las transferidas por la Administración del Estado según la legislación de régimen local, disponía la Comunidad Autónoma, de conformidad con lo que señalaba la regla 8. ${ }^{a}$ del artículo 27 del Estatuto de Autonomía y, también, en desarrollo de las bases establecidas en la Ley 7/1985, de 2 de abril, y, en concreto, en el marco de lo establecido en el Título IV y en los artículos 13, 20.2, 32.2, 29 y 30 de la citada Ley, tal y como indica su Disposición Adicional Primera.

No obstante, el objeto del texto presentado no era únicamente establecer un desarrollo legislativo respetuoso con las reglas básicas, sino que pretendía conseguir un ordenamiento local integrado que facilitara su aplicación a los diversos agentes que intervienen en ella y, sirviera, al propio tiempo, para la necesaria y deseada racionalización de las Administraciones públicas.

El Proyecto de Ley Municipal planteaba, con realismo - lo que será una característica constante de las normas reguladoras de la materia-, la preocupante estructura municipal en su Exposición de Motivos, que, luego - según ya hemos avanzado-, se reproducirá en la Ley vigente, detectando el problema y proponiendo como medidas más adecuadas el fomento a la integración de los municipios, así como su supresión.

\footnotetext{
Además, los dos grupos parlamentarios citados también presentaron un buen número de enmiendas parciales. Vid. Boletin Oficial de las Cortes de Castilla y León, III Legislatura, n. ${ }^{\circ} 242$, de 24 de marzo de 1995.

${ }^{27}$ Vid. Boletin Oficial de las Cortes de Castilla y León, III Legislatura, $n .^{\circ} 244$, de 7 de abril de 1995.

La justificación que ofreció el Consejero de Presidencia y Administración Territorial para retirar el Proyecto de Ley antes de que comenzara su discusión parlamentaria puede verse en Diario de Sesiones de las Cortes de Castilla y León, III Legislatura, n. ${ }^{\circ}$ 76, de 30 de marzo de 1995, p. 329.
} 
Sin embargo, el hacedor del Proyecto de Ley reconocía, de manera expresa, que la reforma de las estructuras municipales a través de una política de fusiones e incorporaciones no sería posible a corto plazo, entre otros motivos, por la distancia existente entre los núcleos, por la falta de conciencia de las propias comunidades municipales y por su voluntad remisa, cuando no opuesta, a desaparecer como Administraciones públicas.

Por ello, dado que la racionalización de las estructuras municipales no es solución suficiente para conseguir la eficaz prestación de los servicios que los ciudadanos de los pequeños municipios demandan con voluntad constante de aproximación a los niveles y calidades existentes en el medio urbano, el Proyecto de Ley se apoyaba en las Mancomunidades municipales, al considerarlas, por su voluntariedad y capacidad de acomodación a las distintas necesidades reales, la fórmula idónea para la prestación de determinados servicios, que, sin necesitar un marco normativo superior, excedan de la capacidad individual de los municipios.

En efecto, otra vez la Junta de Castilla y León - proponente del texto normativo que analizamos--, pese a dar claras muestras de consciencia de la entidad del problema, se pronunciaba en favor de la asociación de municipios a través de las Mancomunidades para reformar las estructuras municipales; una medida que, desde luego, no es traumática pero que, a mi juicio, resulta notoriamente insuficiente para solucionar el grave problema planteado.

El texto que analizamos consta de setenta y un artículos distribuidos en siete títulos, más tres disposiciones adicionales, dos transitorias, una derogatoria y otra final, así como una exposición de motivos que no dudamos en calificar de acertada e, incluso, brillante.

La exposición de motivos describe con realismo y de manera lúcida la situación municipal de la Comunidad Autónoma, hasta el punto de que —como ya hemos señalado- buena parte de su contenido se incorporará a la Ley vigente, así como el contenido de este Proyecto de Ley.

El texto normativo remitido a las Cortes de Castilla y León era, sobre todo, un intento pragmático para impulsar una operación de reordenación municipal. Ahora bien, en ningún momento el redactor del Proyecto de Ley esconde los problemas con que se encuentra para llevar a cabo tal operación y, de ahí, que opte por el apoyo a las Mancomunidades municipales como forma de paliar el problema.

Regulaba con cierta profundidad las Entidades de ámbito territorial inferior al municipio en un sentido abierto y flexible posibilitando su crea- 
ción siempre que exista un sustrato material mínimo y una voluntad de autoadministración. Denomina a este tipo de Entidades locales, de manera ciertamente original, como "Comunidades vecinales», con la pretensión de, incluso a través de la propia denominación - «excluyendo términos que induzcan a una consideración peyorativa de las mismas», dirá la exposición de motivos-, dignificar sus características institucionales, de modo que su existencia constituya un aliciente para los vecinos de los núcleos y para los propios Ayuntamientos, tratando al propio tiempo de impedir la utilización insolidaria de esta fórmula organizativa en perjuicio del resto de los habitantes del municipio.

También —con acierto, en mi opinión- regula, debido al elevado número de pequeños municipios, determinados regímenes municipales especiales como es el caso del concejo abierto y de los municipios con población inferior a 5.000 habitantes.

El Proyecto de Ley dedica su título II a la creación y supresión de municipios y a las alteraciones parciales de sus términos. La mayor parte de su contenido - por no decir prácticamente su totalidad - se verán reproducidos en la vigente Ley de Régimen Local, por lo que demoramos su estudio a un epígrafe posterior.

Pretendemos destacar en las páginas que siguen la regulación que el Proyecto de Ley hace de las Entidades supra e inframunicipales, es decir, los Títulos V y VI, que contemplan tales figuras. El primero, porque, como ya ha sido destacado, contiene la gran apuesta que el redactor del texto normativo hace para ofrecer solución a la estructura territorial municipal. Y, el segundo, porque regula con cierta originalidad y profusión las Entidades de ámbito territorial inferior al municipio, hasta el momento bastante huérfanas de regulación.

El Título V del Proyecto recoge a las Mancomunidades y a otras entidades asociativas ${ }^{28}$.

En el capítulo I, en la parte relativa a las disposiciones generales, se ofrece el concepto de Mancomunidad como asociación de municipios que éstos forman voluntariamente para la ejecución en común de obras y servicios determinados de su competencia, sin que puedan asumir la totalidad de la misma, atribuyéndolas, además de la consideración de Entidad local y personalidad y capacidad jurídica plena para el cumplimiento de

${ }^{28}$ Desde el punto de vista doctrinal, vid., sobre este tema, F. SOSA WAGNER, «Mancomunidades y otras formas asociativas», Tratado..., I, cit., pp. 1041-1048. 
sus fines específicos, las potestades del artículo 4.1 de la Ley $7 / 1985$, de 2 de abril, a saber:

— potestad reglamentaria y de autoorganización;

- potestad tributaria y financiera;

— potestad de programación o planificación;

- potestad expropiatoria condicionada a que sus acuerdos sean ratificados por la Junta de Castilla y León;

- potestad de ejecución forzosa y sancionadora;

— potestad de revisión de oficio de sus actos y acuerdos;

— inembargabilidad de sus bienes y derechos en los términos previstos en la Ley.

Asimismo, en este capítulo - en concreto, en el art. 32 - se recogen diversas medidas de fomento para la constitución y funcionamiento de este tipo de Entidades Locales. Dichas medidas son muy similares a las que ya recogía el Decreto de fomento de las Mancomunidades municipales examinado con anterioridad. De una parte, la Junta de Castilla y León, a través de la Consejería de Presidencia y Administración Territorial, prestará la asistencia técnica y jurídica que para la constitución y funcionamiento de Mancomunidades soliciten los municipios que pretendan constituirlas o, en su caso, la propia Mancomunidad. De otra, en la concesión de ayudas a las Entidades locales por la Junta de Castilla y León, directamente o en cooperación con las Diputaciones provinciales, se dará preferencia a aquellas que financien obras y servicios municipales cuya realización o prestación sea mancomunada.

Los capítulos II y III de este Título recogen, respectivamente, el procedimiento de creación y la modificación y supresión de las Mancomunidades.

Las reglas previstas para su creación son las siguientes:

En primer término, la iniciativa para la constitución de Mancomunidad deberá ser refrendada por cada uno de los municipios que la asuman mediante acuerdo adoptado por mayoría absoluta del número legal de miembros de las respectivas Corporaciones locales, que contendrá la designación de uno de ellos como representante del Ayuntamiento en la Comisión Promotora.

Será este órgano el encargado de la tramitación del procedimiento hasta la constitución de los órganos de gobierno de la Mancomunidad. 
En segundo lugar, la elaboración de los Estatutos corresponderá a una Asamblea a la que serán convocados por el Presidente de la Comisión Promotora —que lo será aquel que resulte elegido de entre sus miembros- todos los concejales de los Ayuntamientos que hayan manifestado su voluntad de mancomunarse. Los acuerdos de esta Asamblea serán adoptados por consenso.

En tercer lugar, el proyecto de Estatutos elaborado por la Asamblea será sometido a información pública por plazo de un mes a efectos de reclamaciones o alegaciones por los vecinos afectados. Simultáneamente se recabará informe de la Diputación o Diputaciones provinciales respectivas, que, de no emitirse en el plazo de un mes, se entenderá favorable al proyecto presentado.

Finalizado el plazo de un mes a que nos acabamos de referir, se remitirá todo lo actuado a la Consejería de Presidencia y Administración Territorial para su informe, que de no emitirse en el plazo de un mes se entenderá, asimismo, favorable.

Por último, el texto de los Estatutos, elaborado por la Asamblea a la vista de las alegaciones e informes recibidos, se remitirá por la Comisión Promotora a las Corporaciones interesadas cuya aprobación por las mismas requerirá acuerdo, que será adoptado por la misma mayoría necesaria para iniciar el procedimiento que hemos descrito, esto es, mayoría absoluta del número legal de los miembros de la Corporación.

Después, adoptados los acuerdos anteriores, el Presidente de la Comisión Promotora remitirá a la Consejería de Presidencia y Administración Territorial una copia del expediente y de los Estatutos de la Mancomunidad para su inscripción en el Registro de Entidades Locales y publicación en el Boletín Oficial de Castilla y León, momento a partir del cual será efectiva su constitución de la que se dará traslado a la Administración del Estado.

En cuanto a la modificación y supresión de este tipo de Entidades locales se seguirá el procedimiento establecido en sus propios Estatutos.

No obstante, el redactor del Proyecto de Ley establecía la obligación de observar, en todo caso, las dos reglas siguientes:

Primera: la iniciativa deberá ser acordada por la mayoría absoluta del número legal de miembros del órgano de gobierno de la Mancomunidad y sometida a información pública e informe de la Diputación o Diputa- 
ciones provinciales interesadas, si se trata de municipios pertenecientes a distintas provincias, y de la Consejería de Presidencia y Administración Territorial.

Segunda: la aprobación definitiva corresponderá a los Ayuntamientos afectados, mediante acuerdo adoptado por mayoría absoluta del número legal de sus miembros, y será efectiva a partir de su publicación en el Boletín Oficial de Castilla y León.

La adhesión y la separación de la Mancomunidad son, lógicamente de acuerdo con la naturaleza de la Entidad local misma de que se trata, actos dispositivos de los Ayuntamientos respectivos, aunque deberá seguirse el procedimiento establecido en los Estatutos de la Mancomunidad, exigiéndose, en caso de la adhesión, que ésta sea aprobada por el órgano de gobierno de la Mancomunidad por mayoría absoluta del número legal de sus miembros $\mathrm{y}$, en ambos casos, el trámite de información pública y el informe de la Consejería de Presidencia y Administración Territorial.

Se establece también la cautela de que la separación de un municipio de la Mancomunidad no podrá producirse si desde su adhesión no ha transcurrido el período de tiempo que los Estatutos han podido establecer.

Las adhesiones y separaciones sólo serán efectivas a partir de su publicación en el Boletín Oficial de Castilla y León, tal y como establece el apartado $3 .^{\circ}$ del artículo 39 , reiterándose, de manera innecesaria, lo ya señalado en las reglas generales que, en todo caso, deben observarse en estos procedimientos, además de las que establezcan los propios Estatutos de la Mancomunidad.

En caso de supresión de una Mancomunidad, se indica en el último de los preceptos que regula este tipo de Entidades locales, ésta mantendrá su personalidad jurídica hasta que por su órgano de gobierno se proceda a la liquidación y distribución de su patrimonio, el acuerdo de todo lo cual se publicará en el Boletín Oficial de Castilla y León.

Finalmente, el capítulo IV de este Título está dedicado a otras entidades asociativas de raigambre en algunas zonas de esta Comunidad Autónoma como son las Comunidades de Villa y Tierra, Comunidad de Tierra, Asocios y otras entidades asociativas tradicionales. Precisamente, por este carácter de tradicionales en Castilla y León, las entidades señaladas se regirán por sus normas consuetudinarias y, sin perjuicio de la autonomía de que disfrutan, deberán ajustar su régimen en cuanto a la formación de presupuestos, rendición de cuentas, liquidación e inventarios a la normativa vigente para las Entidades Locales y siéndoles de aplicación 
supletoria los preceptos relativos a las Mancomunidades en cuanto a la modificación de sus Reglamentos o Estatutos y a las potestades y ayudas.

En fin, como se ha podido observar, el redactor del Proyecto de Ley no ha sido demasiado original a la hora de regular las Mancomunidades municipales, no ha aportado - si asi se quiere expresar - ninguna novedad, limitándose a transcribir lo dispuesto por el legislador del Estado. Ahora bien, en su descargo debe resaltarse que, por el carácter básico de los preceptos de la normativa estatal reguladores de esta figura que, además, han adoptado una fórmula excesivamente rígida ${ }^{29}$, apenas disponía del espacio necesario para introducir diferencias o modulaciones que le permitieran una regulación más adecuada a las necesidades del territorio. Desde este punto de vista, era más respetuoso con la voluntad de los municipios que se querían asociar que otros legisladores autonómicos que, por ejemplo, han dispuesto que la norma de constitución y funcionamiento de la Mancomunidad deberá ser aprobada por el órgano de gobierno de la Comunidad Autónoma.

Las Entidades de ámbito territorial inferior al municipio que, desde el Estatuto municipal de 1924 recibieron la denominación de Entidades Locales Menores ${ }^{30}$, son reguladas - como hemos señalado- en el Título VI del Proyecto de Ley con la denominación, ciertamente original, de «Comunidades vecinales». Pero, la originalidad de la regulación que hace el redactor de la Ley Municipal de Castilla y León se acaba aquí, pues el resto de los contenidos no se apartan de las bases establecidas por el legislador estatal en los artículos 45 de la Ley 7/1985, de 2 de abril, 38 a 45 del Real Decreto legislativo 781/1986, de 18 de abril, por el que se aprueba el Texto refundido de las disposiciones legales vigentes en materia de régimen local y 40 a 50 del Real Decreto 1690/1986, de 11 de julio, por el que se aprueba el Reglamento de Población y Demarcación Territorial de las Entidades locales.

El capítulo I, dedicado a las disposiciones generales, les atribuye la consideración de Entidad local, personalidad y capacidad jurídica para el ejercicio de sus competencias, así como - siguiendo al resto de las normas de las Comunidades Autónomas ${ }^{31}$ - las potestades administrativas

\footnotetext{
29 En este sentido, F. SOSA WAGNer, «Las Mancomunidades...», cit., p. 1043.

30 J. FARIÑA JAMARDO, «La administración de los intereses peculiares en las tradicionales comunidades de aldea", Jornadas sobre Administración Local en Castilla y León: Las Entidades Inframunicipales, Junta de Castilla y León, Consejería de Presidencia y Administración Territorial, Valladolid, 1986, p. 21.

31 En este mismo sentido, V. Rodriguez Cativiela, «Las Entidades Locales Menores en Aragón: situación y perspectivas», $R A A P, \mathrm{n}^{\circ}$ 5, 1994, pp. 451 y 452.
} 
que el artículo 4.1 de la Ley 7/1985, de 2 de abril, confiere a las Entidades locales básicas, salvo la potestad expropiatoria, que únicamente la ostentarán en el ejercicio de competencias delegadas por el municipio de que dependen y, además, debiendo ser ratificados sus acuerdos por el Ayuntamiento.

Las competencias que las Comunidades vecinales ostentarán se clasifican por el redactor del Proyecto de Ley en propias y delegadas.

Las primeras, atribuidas ex lege, son:

a) La administración y conservación de su patrimonio, incluido el forestal, y la regulación del aprovechamiento de sus bienes comunales.

b) La vigilancia, conservación y limpieza de vías urbanas, caminos rurales, fuentes, lavaderos y abrevaderos.

Las delegadas podrán versar sobre la ejecución de obras y la prestación de servicios que sean de su exclusivo interés, prohibiéndose la delegación de las competencias municipales relativas a ordenación, gestión y disciplina urbanística.

Para que la delegación pueda llevarse a cabo es necesario el informe previo de la Diputación provincial, debiéndose especificar en el acuerdo de delegación las formas de control del ejercicio de las competencias delegadas, así como los medios que el municipio ponga a disposición de las Entidades inframunicipales.

Finalmente, para la efectividad de la delegación el redactor del texto normativo exige la previa aceptación de la Comunidad vecinal interesada.

Los capítulos II y V del Título regulador de las Comunidades vecinales recogen, principalmente, los procedimientos de creación y de modificación y supresión de este tipo de Entidades inframunicipales, respectivamente.

El artículo 47 del Proyecto de Ley Municipal, precepto cabecera del capítulo dedicado a la creación de las Comunidades vecinales, señala, en primer lugar, qué debe entenderse por este tipo de Entidades y, en segundo término, los requisitos que, en todo caso, deberán reunir para constituirse como tales.

Por Comunidades vecinales entiende este texto aquellos núcleos de población que, en el término municipal, estén separados de aquél donde radique la capitalidad y cuente con características específicas dentro del 
municipio. Son instrumentos para la representación y gestión de intereses específicos de los vecinos de cada núcleo de población y elementos de descentralización de la administración municipal ${ }^{32}$.

Las Comunidades vecinales podrán constituirse en alguno de los siguientes casos:

a) Cuando se suprima el municipio a que pertenezcan.

b) Cuando por alteración de los términos municipales pasen dichos núcleos a formar parte de otros municipios, $y$

c) Cuando se solicite con arreglo a lo que se establece en el artículo 49 .

Y, además, deberán reunir los requisitos siguientes:

a) El conjunto de edificaciones que formen el núcleo estará separado de los restantes del municipio, sin que, en ningún caso, exista continuidad.

b) Contar con un territorio y recursos que garanticen el cumplimiento de los fines para los que se cree.

c) Existencia de bienes, derechos o intereses peculiares y propios de los vecinos del núcleo, distintos de los comunes al municipio que puedan justificar la constitución.

El texto también establece, en sentido negativo, que no podrán constituirse en Comunidades vecinales ni los núcleos de población donde radique la capitalidad del municipio ni las urbanizaciones de iniciativa particular.

A continuación el texto determina el procedimiento de creación, cuya iniciativa corresponderá a la población interesada o al Ayuntamiento correspondiente.

Por población interesada se entiende la constituida por los vecinos residentes en el núcleo que pretende constituirse como Comunidad vecinal.

La iniciación del procedimiento por los vecinos del núcleo requerirá petición escrita formulada por la mayoría de los que residan en él, acom-

32 Una propuesta diferente a la que establece la legislación de régimen local vigente puede verse en J. ROSA MORENO, «Aproximación histórica a la articulación orgánica de los núcleos separados de población», REALA, n. ${ }^{\circ} 262,1994$, pp. 219-245. 
pañada de una memoria donde se justifique la concurrencia de los requisitos exigidos. La petición y memoria se dirigirán al Ayuntamiento para su tramitación.

En cuanto a la iniciativa municipal debe destacarse, en primer lugar, que se requerirá acuerdo de la Corporación municipal, fundado en una memoria justificativa, adoptado por la mayoría absoluta del número legal de sus miembros, tal y como establece el artículo 47.2 de la Ley $7 / 1985$, de 2 de abril; y, en segundo término, que si la iniciativa no proviniera de él deberá pronunciarse sobre la iniciativa y las alegaciones presentadas, después del trámite de información pública y del informe de la Diputación provincial, mediante acuerdo adoptado por la misma mayoría señalada con anterioridad. Ahora bien, téngase presente que no se exige la aprobación o acuerdo favorable municipal. La razón - como ha destacado Adolfo SÁNCHEZ MORÓN refiriéndose a la normativa estatal, pero que estimamos también aplicable aquí ${ }^{33}$-, es simple: la constitución de una Entidad de este tipo es, en todo caso, un asunto de interés común de los vecinos del municipio, el Ayuntamiento debe tener garantizado su derecho a intervenir en cuantos asuntos afectan directamente al círculo de sus intereses y, por tanto, debe ser oído. Sin embargo, la creación de este tipo de Entidades no es una cuestión de autoorganización municipal, sino de organización territorial; es decir, excede del interés peculiar y específico del municipio y, en consecuencia, no tiene por qué estar supeditada a su criterio o decisión.

La resolución que ponga fin al procedimiento contendrá pronunciamiento expreso sobre denominación y límites territoriales de la Comunidad vecinal, así como sobre la separación patrimonial que corresponda y será adoptada por la Junta de Castilla y León a propuesta de la Consejería de Presidencia y Administración Territorial, publicándose en el Boletín Oficial de Castilla y León y en el Boletín Oficial de la Provincia correspondiente.

En cuanto a su supresión, se producirá cuando los núcleos que le sirven de base dejen de reunir los requisitos que para su existencia exige el artículo 47.2 del texto que analizamos y expuestos en páginas anteriores $\mathrm{y}$, además, en los siguientes supuestos:

a) Incumplimiento continuado y manifiesto de las competencias que detentan.

33 «Municipios y entidades de ámbito territorial inferior al municipal, en la nueva Ley Reguladora de las Bases del Régimen Local», Jornadas sobre Administración Local..., cit., p. 15. 
b) Cuando celebradas elecciones locales, hubiesen quedado sin cubrir los órganos rectores de la Entidad por falta de candidaturas.

c) Cuando se aprecien notorios motivos de necesidad económica o administrativa.

d) Cuando así lo solicite la mayoría de los vecinos.

El procedimiento a seguir en este supuesto será el mismo que el previsto para su creación con la única singularidad de que también puede ejercer la iniciativa la Junta de Castilla y León, previo informe del Órgano consultivo superior de la Comunidad Autónoma o, en su defecto, del Consejo de Estado.

En cuanto a la modificación de este tipo de Entidades inframunicipales, la única previsión que contiene el Proyecto de Ley es que el procedimiento legalmente establecido es el mismo que el exigido para su constitución.

El capítulo III de este Título está dedicado a la organización y funcionamiento de las Comunidades vecinales.

Las disposiciones que contiene el Proyecto de Ley respecto de esta materia son únicamente las que establece la normativa estatal básica. Por una parte, la necesaria existencia de un órgano unipersonal ejecutivo, que el redactor de este texto concreta en el Alcalde Pedáneo elegido directamente por los vecinos de la correspondiente Comunidad Vecinal por sistema mayoritario; y, de otra, la existencia, asimismo obligatoria, de un órgano colegiado de control, la Junta Vecinal, integrada por el Alcalde pedáneo y dos o cuatro vocales, según que el núcleo sea inferior o no a 250 residentes. En la elección de los miembros de este órgano se introduce un cambio: se hará de conformidad con los resultados de las elecciones para Alcalde Pedáneo, pretendiendo con ello evitar situaciones de ingobernabilidad, como consecuencia de que dicha elección toma en consideración los resultados de las elecciones para el Ayuntamiento. Con objetivo análogo, y también de colmar una laguna existente en la ordenación actual se contempla la posibilidad de la moción de censura al Alcalde Pedáneo.

Por último, el capítulo IV contiene distintas previsiones relativas a los recursos de este tipo de Entidades que son los siguientes:

a) Ingresos procedentes de su patrimonio y demás procedentes de Derecho privado. 
b) Tasas y precios públicos.

c) Contribuciones especiales.

d) Subvenciones y otros ingresos de Derecho público.

e) Ingresos procedentes de operaciones de crédito.

f) Multas.

g) Aportaciones municipales y participaciones en los ingresos del municipio.

En fin, después de examinado el texto propuesto por la Junta de Castilla y León sólo nos resta insistir en la escasa originalidad que ha desplegado el redactor de este texto normativo para regular las materias que trata. Se ha limitado simplemente a desarrollar - cuando no a reproducirlas bases establecidas por el Estado, pero sin introducir las matizaciones necesarias para acomodarlas a las necesidades de la organización territorial local de esta Comunidad.

\section{La Ley de Régimen Local de Castilla y León: Ley 1/1998, de 4 de junio}

Poco más de un año después, en la siguiente Legislatura - la IV.a - - la Junta de Castilla y León, en ejercicio de su poder de iniciativa legislativa, presentó un Proyecto de Ley de Régimen Local ${ }^{34}$, que, esta vez sí, tras la correspondiente tramitación parlamentaria, vería la luz en las páginas del Boletín Oficial de Castilla y León del día 11 de junio de 1998 como la Ley 1/1998, de 4 de junio, de Régimen Local de Castilla y León.

En realidad, como veremos, el proyecto presentado y el texto finalmente aprobado poco se diferencia del Proyecto de Ley Municipal que hemos examinado en el epígrafe anterior, aunque algunas novedades contiene de las que, lógicamente, daremos cuenta en las páginas que siguen.

La Ley aprobada consta de ciento diez artículos, distribuidos en nueve títulos, además de una Exposición de Motivos, doce disposiciones adicionales, cuatro transitorias, una derogatoria y otra final.

Las materias que regula son, prácticamente, las mismas que se contemplaban en el Proyecto de Ley anteriormente examinado: la creación,

${ }^{34}$ Boletin Oficial de las Cortes de Castilla y León, IV Legislatura, $\mathbf{n} .^{\circ} 111$, de 23 de diciembre de 1996. 
supresión y alteración de términos municipales, las mancomunidades municipales y otras entidades asociativas y las entidades de ámbito territorial inferior al municipio; además, la Ley recoge, con las correspondientes modificaciones que la experiencia ha aconsejado, la Ley 6/1986, de 6 de junio, Reguladora de las Relaciones entre la Comunidad de Castilla y León y las Entidades locales, configurándose así el título IX y último de esta Ley.

El Proyecto de Ley de Régimen Local no fue muy bien recibido por los grupos de la oposición, ya que presentaron tres enmiendas a la totalidad con devolución del texto y más de 400 enmiendas parciales, de las que 56 fueron presentadas por el propio grupo parlamentario que apoyaba al Gobierno autonómico, si bien, en general, eran poco relevantes, limitándose, más que nada, a cuestiones de estilo.

Socialistas, Izquierda Unida y el grupo mixto (Sr. Otero Pereira) fueron los firmantes de las enmiendas a la totalidad.

El Sr. Otero Pereira, tras calificar el Proyecto de Ley presentado de «la gran chapuza» ${ }^{35}$, consideraba necesario - y éste era el argumento fundamental de su enmienda - que se hubieran presentado dos proyectos de ley: uno de régimen local de Castilla y León y otro, concreto y específico, para las entidades de ámbito local inferior al municipio.

A su juicio, el gran número de entidades inframunicipales existentes en la Comunidad Autónoma y, sobre todo, en la provincia de León (el procurador enmendante era miembro de la Unión del Pueblo Leonés) hacía imprescindible una Ley que se ocupara de este tipo de entidades locales con afán de potenciarlas y no de suprimirlas, como en su opinión pretendía el Proyecto de Ley presentado.

La enmienda a la totalidad de Izquierda Unida destacaba la - en su opinión - falta de coherencia que existía entre la Exposición de Motivos y el texto articulado del Proyecto de Ley, hasta el punto de manifestar que no debían haber sido escritos por la misma persona, ya que la primera esbozaba unos principios fundamentales de la Ley, pero que luego no se veían reflejados en el texto, incluso supone en muchos casos - decíauna regresión respecto a la penosa situación actual ${ }^{36}$.

Además, se oponía, sintéticamente, porque dejaba pasar la oportunidad de estructurar la comarca como entidad básica de nuestra ordenación

${ }^{35}$ Diario de Sesiones, IV Legislatura, n. ${ }^{\circ}$ 45, de 17 de abril de 1997, p. 2768.

${ }^{36}$ Diario de Sesiones, cit., p. 2770. 
territorial; por el pobre tratamiento que se hace acerca de las mancomunidades; por el exagerado papel que se atribuye a la provincia y, en último lugar, porque el objetivo fundamental del Proyecto de Ley (el favorecimiento de la integración de los municipios y la consiguiente racionalización de las estructuras municipales) tampoco se aborda con efectiva voluntad, pues se limita a regular cuestiones burocráticas, mecanicistas, técnicas, sin ofrecer ni un solo aliciente, ni ayuda real alguna para que sean efectivas tales integraciones ${ }^{37}$.

Finalmente, la tercera enmienda a la totalidad presentada por el grupo parlamentario Socialista tenía su justificación en las graves carencias que, a su parecer, contenía el Proyecto de Ley presentado.

En primer lugar, consideraba que no arbitraba soluciones efectivas para la ordenación municipal. Se trata - manifestaba - de un texto que sale descompensado, un texto extremadamente prolijo en lo anecdótico y nada comprometido en lo sustancial; un texto que, como mucho, alcanza a enunciar los problemas que acucian al régimen local de Castilla y León ${ }^{38}$.

En segundo término, constataba que no afrontaba el tema de la financiación municipal, limitándose el texto en esta materia a introducir una disposición adicional que establecía un plazo de dos años para presentar un Plan de Cooperación Local, «cuando es imposible que demos pasos en la mejora de la ordenación territorial de nuestra Comunidad Autónoma, si no somos capaces y asumimos aquí, como Gobierno Regional, la necesidad de incrementar la dotación económica, la financiación de las Corporaciones locales») ${ }^{39}$.

Y, en tercer lugar, señalaba que no afronta el necesario impulso descentralizador en pro de las Corporaciones locales para hacer efectivo el principio de autonomía municipal.

El portavoz del grupo Socialista concluía manifestando que «frente a estas graves carencias el proyecto se muestra prolijo en la regulación de aspectos suficientemente contemplados en la legislación del Estado, limitándose a su reproducción en el texto propuesto por la Junta» ${ }^{40}$.

\footnotetext{
37 Diario de Sesiones, cit., p. 2771.

38 Diario de Sesiones, cit., p. 2773.

39 Diario de Sesiones, cit., pp. 2774 y 2781.

40 Diario de Sesiones, cit., p. 2774.
} 
Por lo que respecta a las enmiendas parciales, el gran número de las presentadas, de todas las clases: adición, sustitución, modificación, etc., y a, prácticamente, la totalidad de los preceptos del Proyecto de Ley, nos impide realizar cualquier intento de sistematización.

La Ley de Régimen Local —calificada por todos como una de las más importantes que se van a debatir en estas Cortes o de enorme importancia para la ordenación del territorio de nuestra Comunidad- parte de un diagnóstico claro e inequívoco, que se refleja en la Exposición de Motivos, buena parte de la cual —como ya hemos señalado — procede del Proyecto de Ley Municipal anterior.

La situación municipal es, de nuevo, descrita con realismo por el legislador castellano y leonés, una situación que ya hemos calificada de gravísima y necesitada de urgentes y drásticas soluciones, pero que el proponente del texto no se atrevió a ofrecer porque estaba convencido de las dificultades prácticas de llevar a cabo un proyecto global de reforma y modernización del mapa municipal por medio de una política de fusiones, que, por otro lado, parece que no reportaría tantos beneficios como se ha mantenido por algunos sectores y en cambio sí produciría problemas de desarraigo, pérdida de identidad, alejamiento y apatía de los ciudadanos ante problemas que afectan a su vida cotidiana, pero que tienen una trascendencia pública ${ }^{41}$.

El Título II de la Ley, bajo la rúbrica «Creación y Supresión de Municipios y Alteraciones de sus Términos», responde directamente al objetivo fundamental de la Ley, que es la ordenación de la estructura territorial municipal.

Está integrado por cinco capítulos: creación de municipios (capítulo I), supresión de municipios (capítulo II), alteraciones parciales de términos municipales (capítulo III), procedimiento (capítulo IV) y medidas de fomento a las fusiones e incorporaciones (capítulo V).

De la regulación que se lleva a cabo en los veintiocho preceptos que componen el Título que analizamos, deben destacarse, cuando menos, dos cuestiones.

En primer término, que la regulación efectuada respeta de forma escrupulosa la estructura municipal de la Comunidad, en el sentido de que

${ }^{41}$ I. LOPEZ ANDUEZA, «Mancomunidades de municipios...», cit., p. 149. 
no contiene disposición traumática alguna, pero no renuncia a conseguir una estructura más racional que asegure a la población que se asienta en nuestros pequeños y numerosos municipios una calidad de vida homologable a la del municipio urbano.

En efecto, el legislador castellano y leonés, al igual que han hecho los de otras Comunidades Autónomas, ha ejercido su potestad legislativa «pro futuro», esto es, ha partido de la situación municipal existente, respetándola, y no dictando ninguna medida extrema que pudiera abocar a la desaparición automática, ex lege, de municipios ${ }^{42}$; pero, de cara al futuro, fija un umbral de población por debajo del cual no es posible la constitución de un nuevo municipio [en concreto, fija la población mínima en 1.000 habitantes, según dispone el art. 10.1.b)], tratando con ello de evitar la aparición de nuevos inframunicipios, $y$, de cara al presente, contempla medidas tendentes a las fusiones e incorporaciones de municipios con población inferior a mil residentes, tales como:

1. ${ }^{\mathrm{a}} \quad$ La creación de un fondo o dotación destinado a acciones directas de fomento y a la concesión de ayudas para una mejor prestación de servicios de los municipios resultantes.

2. ${ }^{a} \quad$ La fijación de preferencias en su favor y a los mismos fines en los regímenes generales de ayudas a municipios que aprueba la Junta de Castilla y León, teniendo prioridad las comunidades entre los núcleos pertenecientes a los municipios fusionados o incorporados y la capitalidad del municipio resultante y aquellas necesidades o servicios derivados directamente de la alteración.

42 La única medida traumática que contemplaba el Proyecto de Ley - si asi puede calificarse- es la que contenía su artículo 25 , que disponía que si persistieran las circunstancias que motivaron la dispensa de la obligación de prestar determinados servicios mínimos, transcurrido el plazo para el que fue concedida, la Junta de Castilla y León iniciaria de oficio el procedimiento de supresión del municipio. Pero, en la tramitación parlamentaria esta disposición desapareció.

Las circunstancias que podían llevar a la Junta de Castilla y León a dispensar temporalmente de la obligación de prestar determinados servicios mínimos, a solicitud —además- de los respectivos Ayuntamientos, eran las siguientes:

a) Que por sus características peculiares, resulte imposible o muy difícil el establecimiento o adecuada prestación de dichos servicios por el propio municipio.

b) Que no sea posible su establecimiento o prestación en breve plazo, aun utilizando procedimientos de asociación con otros municipios o de cooperación con otras Administraciones Públicas.

c) Que el esfuerzo fiscal no sea inferior a la media de los municipios de características análogas de la Comunidad Autónoma. 
3. La asistencia y asesoramiento adecuados, por parte de las Diputaciones Provinciales, para facilitar la integración y la eficaz prestación de los servicios municipales a los municipios resultantes, así como el establecimiento, en su favor, de prioridades y preferencias en los Planes Provinciales de Cooperación.

4. ${ }^{\mathrm{a}} \quad$ La promoción de convenios y acuerdos oportunos para una eficaz coordinación de las anteriores medidas de fomento con las que pueda establecer el Estado conforme al artículo 13.3 de la Ley 7/1985, de 2 de abril, y

5. Asimismo, la promoción de convenios y acuerdos de cooperación con los municipios resultantes para la gestión de su patrimonio.

$\mathrm{Y}$, en segundo lugar, que la regulación contenida apenas se diferencia de la establecida en la normativa estatal que, como es sabido, es la dispuesta en los artículos 13 de la Ley 7/1985, de 2 de abril, 2 a 9 del Texto Refundido de Régimen Local y 2 a 16 del Reglamento de Población y Demarcación Territorial. Es decir, podemos afirmar que no aporta nada nuevo.

No obstante, sí debe ser subrayado, pues constituye una cierta originalidad del legislador castellano y leonés, el planteamiento sistemático que hace de esta materia.

Tradicionalmente, nuestra legislación de régimen local, bajo la denominación común de «alteraciones de términos municipales», ha regulado la diversidad de conceptos que tienen por finalidad el ejercicio de esta operación de ordenación territorial, mientras que ahora esta misma diversidad es acogida por la Ley en dos rúbricas distintas: una, creación de municipios y, otra, supresión de municipios, dejando entrever la clara voluntad del legislador de promover la segunda y, por el contrario, restringir la primera.

Así es. Mientras para la creación de un municipio por la segregación de parte del territorio de otro u otros la Ley, en su artículo 10, exige que existan motivos de interés público y que concurran todas y cada una de las condiciones siguientes:

a) Que se trate de uno o varios núcleos de población territorialmente diferenciados e históricamente consolidados.

b) Que el núcleo o núcleos a segregar cuenten con una población mínima de mil residentes.

c) Que el municipio cuya creación se pretenda cuente con territorio y recursos suficientes para el adecuado cumplimiento de las competencias y servicios municipales. 
Para la supresión de un municipio por su incorporación a otro u otros limítrofes será suficiente que se dé sólo alguna de las siguientes causas:

a) Falta de población o descenso acusado y progresivo de la misma.

b) Confusión de sus núcleos de población con otro u otros como consecuencia del desarrollo urbanístico.

c) Insuficiencia de medios para prestar los servicios mínimos exigidos por la Ley.

d) Falta reiterada de candidatos en las elecciones de sus órganos de gobierno o la falta de funcionamiento de los mismos.

e) Existencia de condiciones económicas, administrativas o de cualquier otro carácter que pudieran hacerla necesaria o conveniente.

De igual manera, para que pueda acordarse la alteración parcial de términos municipales mediante la segregación de parte del territorio de un municipio para agregarlo a otro limítrofe será suficiente concurra alguna de las siguientes causas previstas en el artículo 15 de la Ley:

a) Confusión de sus núcleos de población como consecuencia del desarrollo urbanístico.

b) Necesidad de dotar a un municipio limítrofe del territorio indispensable para ampliar los servicios existentes o instalar aquellos nuevos que imperativamente hubiera de prestar como consecuencia de un aumento de población.

c) Existencia de condiciones económicas, administrativas o de cualquier otro carácter que pudieran hacerla necesaria o conveniente.

Y, en fin, la creación de un municipio por la fusión de otros limítrofes (art. 11) o la supresión por la fusión con otro u otros limítrofes (art. 14) será suficiente que se dé alguna de las siguientes causas:

a) Cuando separadamente carezcan de capacidad o recursos suficientes para atender los servicios mínimos exigidos por la Ley.

b) Cuando sus núcleos de población se confundan como consecuencia del desarrollo urbanístico, y 
c) Cuando existan notorios motivos demográficos, económicos, administrativos o de cualquier otro carácter que pudieran hacerla necesaria o conveniente.

Por lo que se refiere a las Mancomunidades y otras Entidades Asociativas, de las que se ocupa el Título VI (arts. 29 a 48) de la Ley, poco innova respecto a lo que disponía el Proyecto de Ley Municipal ya analizado y, por ello, a lo más arriba expuesto nos remitimos.

Sin embargo, sí queremos resaltar que, si bien el legislador castellano y leonés vuelve a optar por esta fórmula para tratar de paliar los problemas de la ordenación municipal existente, lo cierto es que «es consciente de que son una solución únicamente parcial a la incapacidad derivada del inframunicipalismo» ${ }^{43}$.

A las Cortes de Castilla y León se le presentaban las cuatro siguientes alternativas:

1. ${ }^{\mathrm{a}} \quad$ Dejar que las cosas siguieran su curso.

2. Dispensar a un número creciente de municipios de prestar aquellos servicios que sean incapaces de gestionar directamente por sí y encomendar ese cometido a otra institución de nivel territorial superior.

3. Limitarse al habitual remiendo de la situación con ayudas y colaboraciones puntuales y discrecionales.

4. ${ }^{\mathrm{a}}$ Buscar fórmulas de superación de estas insuficiencias por los propios municipios interesados $\mathrm{y}$, mediante pactos voluntarios, unir esfuerzos con otras entidades iguales para abordar obras y servicios de interés común y programas y proyectos de actuación compartida, fortaleciendo su posición política frente a las Administraciones de nivel superior.

Entre todas ellas apostó por la cuarta alternativa, que pretende frenar el fenómeno segregacionista e impulsar las Mancomunidades de municipios.

Pues bien, se pretende impulsar este tipo de entidades locales, teniendo en cuenta que deben proyectarse sobre una doble finalidad:

a) La Mancomunidad de municipios, como una fórmula asociativa para la prestación de servicios.

${ }^{43}$ Diario de Sesiones, cit., p. 2767. 
b) La Mancomunidad de municipios como instrumento de superación de las estructuras municipales.

Es en este último sentido en el que debe inscribirse cierta novedad de la Ley ${ }^{44}$, recogida en su artículo 32 , que dispone que «aquellas Mancomunidades cuyo ámbito territorial concuerde sustancialmente con espacios de ordenación territorial para la prestación de servicios estatales, autonómicos o provinciales, podrán ser declaradas de interés comunitario». De este modo las Mancomunidades pueden servir como un ámbito territorial adecuado para la realización de obras y servicios por parte del resto de Administraciones públicas, al tiempo que puede contribuir, mediante el ejercicio de la solidaridad y de la acción en común, a constituir ámbitos territoriales supramunicipales más adecuados para la gestión de las competencias municipales y que supongan la base para una alternativa futura a la actual organización territorial.

Es ésta - nos parece- una fórmula imaginativa que debe ser explota$\mathrm{da}$, pues entendemos que tiene la potencialidad suficiente para avanzar en la modificación de la estructura territorial municipal de nuestra Comunidad Autónoma.

Ahora bien, la remisión a la potestad reglamentaria de la Junta de Castilla y León del establecimiento de los requisitos que deberán reunir las Mancomunidades para ser declaradas de interés comunitario y los beneficios derivados de tal declaración, aún no ejercida, nos impide profundizar más en esta cuestión.

En cuanto a la Entidades de ámbito territorial inferior al municipio, reguladas en el Título VII de la Ley (arts. 49 a 70), el legislador castellano y leonés aporta como única novedad que merece ser destacada, en relación a lo ya expuesto cuando hemos tratado este tipo de entidades en el Proyecto de Ley Municipal, la recuperación de la denominación tradicional, al menos desde el Estatuto Municipal de 1924, de Entidades Locales Menores.

La Ley las considera como verdaderos entes públicos, dotados de personalidad jurídica propia e independiente, y en cierto modo autónomos, respecto del municipio en cuyo territorio se integran. No se las considera

\footnotetext{
44 Seguramente el legislador castellano y leonés se ha inspirado en las Leyes 6/1987, de 15 de abril, de Mancomunidades de Municipios en Aragón (la primera Ley de Mancomunidades en España) y 5/1991, de 27 de febrero, de Comarcas de Aragón, en las que se utiliza la Mancomunidad como base para las futuras comarcas.
} 
órganos de gestión desconcentrada ni son tampoco un fenómeno de autoorganización, sino un fenómeno de organización territorial.

Finalmente, bajo la rúbrica de «Regímenes Municipales Especiales» (Título VIII, arts. 72 a 80), la Ley aborda, de modo singular, el de los municipios que funcionan en régimen de concejo abierto. Sobre este particular la Ley Reguladora de las Bases de Régimen Local, como es sabido, generalizó este sistema de funcionamiento en todos los municipios de población inferior a cien habitantes, según determina su artículo 29.1.a).

Pues bien, la Ley de Régimen Local de Castilla y León se aparta de esta tesis, en el sentido de no imponer este sistema a las Entidades Locales Menores con población inferior a cien habitantes $y$, en este orden de cosas, el artículo 72.1 dispone que funcionarán necesariamente conforme a este régimen «aquellas Entidades Locales Menores... que tradicionalmente lo vienen utilizando».

De los restantes regímenes especiales, merece nuestra atención, por la incidencia que pueden tener en la conformación de una nueva ordenación territorial, el de «aquellos municipios que cuenten con servicios culturales, educativos, sanitarios, sociales, administrativos o de otra naturaleza mediante los cuales se satisfaga la demanda de los residentes en otros municipios limítrofes» (art. 79 de la Ley).

Respecto de estos municipios, la Ley posibilita que puedan ser receptores de competencias transferidas o delegadas por la Comunidad Autónoma, a tenor de lo dispuesto en el artículo 84.1.c) de la Ley, y, además, que puedan ser objeto de un tratamiento preferencial por parte de la Junta de Castilla y León.

En suma, se posibilita el reforzamiento de este tipo de municipios, que se han dado en llamar «municipios cabecera de comarca», con la importancia que puede tener desde un enfoque de organización territorial.

\section{LA ORDENACIÓN DEL TERRITORIO}

No podemos concluir este trabajo sin dar cuenta, al menos, del intento del legislador castellano y leonés de incidir en la situación municipal de la Comunidad Autónoma a través de otro instrumento normativo que tiene su fundamento - no, como los examinados hasta ahora, en las competencias en materia de Régimen local- en el título más amplio y general de la Ordenación del Territorio, que la Comunidad Autónoma tiene asu- 
mido en virtud de lo dispuesto en el artículo 32.1.2. ${ }^{\circ}$ del Estatuto de Autonomía.

Me refiero, en concreto, a la Ley 10/1998, de 5 de diciembre, de Ordenación del Territorio de la Comunidad Autónoma de Castilla y León, que también es consciente de la fragmentación administrativa municipal, a la que califica, en su Exposición de Motivos, de «singularidad territorial» que justifica, entre otras, un tratamiento integrador de las perspectivas sectoriales que supere su inherente parcialidad.

Ahora bien, el intento del legislador castellano y leonés para superar la actual planta municipal no va a estar tanto directamente en la citada Ley como en la primera figura del sistema de ordenación territorial que dicho texto establece: las Directrices de Ordenación del Territorio, que se conciben como el instrumento para sintetizar y orientar la política territorial de la Comunidad, de acuerdo con las políticas sociales, económicas y culturales vigentes (arts. 8 a 13 de la Ley).

Pues bien, las Directrices de Ordenación del Territorio ${ }^{45}$, en fase aún —en el momento en que se escriben estas páginas - de información pública y audiencia a las Administraciones Públicas, a tenor de lo dispuesto por la Orden de 24 de noviembre de 2000 de la Consejería de Fomento ( $B O C y L$ de 28 de diciembre), dedican en el capítulo que versa sobre las «Directrices Esenciales» un interesante apartado a las «nuevas estrategias territoriales para los espacios rurales», pronunciándose en favor de las que denomina Cabeceras de las Áreas Funcionales de Castilla y León, que concibe como «una red de núcleos con influencia supramunicipal que actúan como centros de prestación de servicios y de dinamización de los espacios rurales».

Desde luego, esta figura - al menos, asi lo parece - tiene mucho que ver con los municipios de régimen especial que contempla el artículo 79 de la Ley de Régimen Local de Castilla y León, los llamados municipios cabecera de comarca y que hemos considerado como una fórmula imaginativa del legislador que debe ser explotada en el intento de cambiar, de manera ciertamente radical, la planta municipal de esta Comunidad Autónoma.

Pero, más importancia que esta figura revisten, a mi juicio, las denominadas Áreas Funcionales de Castilla y León, que constituyen ámbitos para la ordenación territorial de escala intermedia entre el nivel regional y

${ }^{45}$ Directrices de Ordenación del Territorio, Junta de Castilla y León, Valladolid, 2000. 
el municipal y que deben asumir un gran protagonismo en la estructura espacial de la Comunidad. Su delimitación surge de las dinámicas territoriales definidas por la intensidad de las relaciones, la funcionalidad de cabeceras que actúan como áreas de centralidad en relación con su ámbito territorial y de la existencia de un cierto grado de homogeneidad interna.

En fin, estas Áreas Funcionales nos recuerdan, también mucho, a otra figura prevista en la Ley de Régimen Local de Castilla y León y que, asimismo, hemos considerado de extraordinaria potencialidad para ofrecer solución a la depauperada situación municipal de nuestra Comunidad Autónoma: son las llamadas Mancomunidades de interés comunitario que contempla el artículo 32 de la Ley.

Entiendo que no con mucho esfuerzo la Junta de Castilla y León debe hacer coincidir las Áreas Funcionales diseñadas en las Directrices de Ordenación del Territorio con las Mancomunidades de interés comunitario, lo que, en mi opinión, redundaría en notable beneficio para esta Comunidad Autónoma.

Cabeceras (municipios cabeceras de comarca) y Áreas Funcionales (Mancomunidades de interés comunitario) definen ámbitos integrados de ciudad y territorio desde los que diseñar y aplicar iniciativas de ordenación y desarrollo imprescindibles para el futuro de Castilla y León y, en particular, para los amplios espacios rurales de la Comunidad. Constituyen ámbitos de actuación idóneos para la aplicación de las iniciativas de cooperación entre lo urbano y lo rural y para la prestación de servicios a los ciudadanos en condiciones de eficacia y eficiencia. 


\section{Jurisprudencia}

REAL-2001, núm. 285. CALONGE VELAZQUEZ, ANTONIO. LA PLANTA MUNICIPAL Y LAS ENTID... 
